\title{
Severe vitamin B12 deficiency in an exclusively breastfed 5-month-old Italian infant born to a mother receiving multivitamin supplementation during pregnancy
}

Sophie Guez, Gabriella Chiarelli, Francesca Menni, Simona Salera, Nicola Principi and Susanna Esposito*

\begin{abstract}
Background: In infants, vitamin B12 deficiency may be due to an inborn error of absorption and metabolism, or nutritional problems.

Case presentation: An exclusively breastfed 5-month-old Italian male infant, who was born after a normal full-term pregnancy to a vegan mother who was apparently daily treated with a multivitamin oral preparation during the second and third trimester, was hospitalised because of poor weight gain, feeding difficulties, severe pallor, muscle hypotonia and somnolence. Upon admission, his weight, length and head circumference were below the third percentile, he had an enlarged liver and spleen, and showed a significant delay in developmental milestones and communicative reactions. He had a hemoglobin level of $4.7 \mathrm{~g} / \mathrm{dL}$ with an MCV of $84.2 \mathrm{fL}$, a white blood cell count of $4,680 / \mathrm{mm}^{3}$, and a platelet count of $45,000 / \mathrm{mm}^{3}$. His serum vitamin B12 level was $57 \mathrm{pg} / \mathrm{mL}$ (normal value $180-500 \mathrm{pg} / \mathrm{mL}$ ) and serum folate level $12.8 \mathrm{ng} / \mathrm{mL}$ (normal value $>3 \mathrm{ng} / \mathrm{mL}$ ). The results of metabolic examinations excluded a cobalamin $C$ disorder, whereas nutritional screening showed a serum iron concentration of $9 \mu \mathrm{g} / \mathrm{dL}$ and serum ferritin of $4 \mathrm{ng} / \mathrm{mL}$. Magnetic resonance imaging of the brain showed mild dilatation of the lateral ventricles with diffuse delayed myelination. The child was diagnosed as having vitamin B12 and iron deficiency due to nutritional inadequacy and was immediately treated with packed red blood cells, intramuscular vitamin B12 injections, and iron supplementation. A few days after the start of therapy, his hemoglobin levels and other hematological parameters rapidly improved, and a clinical improvement was observed within few weeks. There was an increase in his achievement of developmental milestones, but his development was still retarded seven months after the start of therapy.

Conclusion: This case underlines the importance of adequately controlling maternal vitamin B12 intake during pregnancy by means of supplementation which, in the case of vegan mothers, should be significantly greater than that usually given. Moreover, the supplementation should be continued during lactation in order to avoid the development of signs of deficiency that may be associated with persistent neurological problems in infants. The case also highlights the need to consider vitamin B12 deficiency in infants with severe anemia even if their hematological parameters do not indicate megaloblastic anemia because the concomitant presence of substantial iron deficiency may modify the characteristics of the anemia.
\end{abstract}

Keywords: Anemia, Iron deficiency, Neurological problems, Vegan diet, Vegan mothers, Vitamin B12 deficiency

\footnotetext{
* Correspondence: susanna.esposito@unimi.it

Pediatric Clinic 1, Università degli Studi di Milano, Fondazione IRCCS Ca'

Granda Ospedale Maggiore Policlinico, Via Commenda 9, Milano 20122, Italy
} 


\section{Background}

Vitamin B12 plays a major role in human intermediary metabolism. It is required to convert methylmalonylCoA to succinyl-CoA (a compound metabolised by the Krebs cycle to produce energy) and to ensure the activity of methionine synthase, an enzyme that catalyses the methylation of homocysteine to form the essential amino acid methionine [1].

Vitamin B12 deficiency leads to the accumulation of methylmalonic acid and homocysteine in blood and urine, and the onset of clinical hematological, neurological and psychiatric manifestations [2]. Vitamin B12 deficiency in infancy may be due to an inborn error of absorption and metabolism, or (more frequently) nutritional problems. The most frequent inborn error is cobalamin $\mathrm{C}$ disorder, which is caused by a mutation of the $M M A C H C$ gene encoding a protein that plays a critical role in the metabolic pathway leading to the formation of succinyl-CoA and methionine [3]. However, most infants with B12 deficiency are born to women with low vitamin B12 levels and have been exclusively breastfed. Vitamin B12 is only found in animal products such as meat, egg, fish and milk [4]. Consequently, the breast milk of mothers who do not consume such products is frequently poor in vitamin B12, and their newborn infants have low vitamin stores.

We describe the case of an exclusively breastfed 5month-old Italian infant with severe pancytopenia and neurological impairment who was born to a vegan mother who had received B12 supplementation during pregnancy but not during lactation.

\section{Case presentation}

This five-month-old male Italian infant was born after a normal full-term (41 weeks) pregnancy with a weight of $2,550 \mathrm{~g}$ (3rd percentile), length of $48 \mathrm{~cm}\left(10^{\text {th }}\right.$ percentile) and head circumference of $35 \mathrm{~cm}\left(25^{\text {th }}\right.$ percentile). His mother, who had been vegan for several years, was apparently daily treated with a multivitamin oral preparation with a multivitamin preparation (Multicentrum, Pfizer Consumer Healthcare, Rome, Italy) during the second and third trimester in order to ensure an intake of $2.5 \mu \mathrm{g}$ of vitamin B12 per day. Unfortunately, this supplementation was stopped after delivery. The child was exclusively breastfed until the fifth month of life, when he was hospitalised because of poor weight gain, feeding difficulties, severe pallor, muscle hypotonia and somnolence. The parents reported that some of these signs had been present from the third month of life. The child was seen by a paediatrician at the age of one month and three months, and physical evaluation resulted normal. Physical examination upon admission confirmed the pallor and revealed that the child was below the 3rd percentile for weight $(4,800 \mathrm{~g})$, length
$(60 \mathrm{~cm})$ and head circumference $(39 \mathrm{~cm})$, had an enlarged liver and spleen, showed a significant delay in the developmental milestones and communicative reactions for his age. He had a hemoglobin level of $4.7 \mathrm{~g} / \mathrm{dL}$ with an MCV of $84.2 \mathrm{fL}$, a white blood cell count of $4,680 / \mathrm{mm}^{3}$ and neutrophil count of $1,900 \mathrm{~mm}^{3}$. His platelet count was $45,000 / \mathrm{mm}^{3}$. The peripheral blood film showed oval macrocytes, anisopoikilocytosis, hypochromia, anisochromia and hyper-segmented polymorphonuclear leukocytes. His serum vitamin B12 level was $57 \mathrm{pg} / \mathrm{mL}$ (normal value $180-500 \mathrm{pg} / \mathrm{mL}$ ) and serum folate level $12.8 \mathrm{ng} / \mathrm{mL}$ (normal value $>3 \mathrm{ng} / \mathrm{mL}$ ). Blood homocysteine was $11 \mu \mathrm{mol} / \mathrm{L}$ (normal value 4$15 \mu \mathrm{mol} / \mathrm{L}$ ) and urinary methylmalonic acid $281 \mathrm{mmol} /$ moL creatinine (normal value $<5 \mathrm{mmol} / \mathrm{moL}$ creatinine). No intrinsic factor antibodies were found. Hormonal and nutritional screening revealed no other deficiency except for a serum iron concentration of 9 $\mu \mathrm{cg} / \mathrm{dL}$ (normal value $>29 \mu \mathrm{g} / \mathrm{dL}$ ) and serum ferritin of $4 \mathrm{ng} / \mathrm{mL}$ (normal value $20-270 \mathrm{ng} / \mathrm{mL}$ ). Thalassemia screening resulted negative. A bone marrow examination showed a reduced number of red line cells with some megaloblasts, a small number of dysplastic megakaryocytes, and dysplastic granulopoiesis with asynchronous maturation processes. Genetic analyses did not find any $M M A C H C$ gene mutations.

Magnetic resonance imaging (MRI) of the brain showed mild dilatation of the lateral ventricles with diffuse delayed myelination that was most marked in the brainstem.

Maternal investigations showed a hemoglobin level of $9.1 \mathrm{~g} / \mathrm{dL}$ with an MCV of $96.4 \mathrm{fL}$, and serum vitamin B12 level of $155 \mathrm{pg} / \mathrm{mL}$ (no data on maternal serum vitamin B12 during pregnancy was available).

On the basis of these data, the child was diagnosed as having vitamin B12 and iron deficiency due to nutritional inadequacy. He was immediately treated with packed red blood cells, intramuscular vitamin B12 injections (at a dose of 1,000 $\mu \mathrm{g} /$ day for two weeks followed by weekly injections at the same dose for six months) and oral iron supplementation (iron sulphate $3 \mathrm{mg} / \mathrm{kg} /$ day for 3 months).

Table 1 shows the patient's clinical and laboratory data upon admission and during follow-up. A few days after the start of therapy, his hemoglobin levels and other hematological parameters rapidly improved, and a clinical improvement was observed after a few weeks. The patient was discharged after 19 days.

In the sixth month of life, the child was weaned and green vegetables as well as fish was introduced in his diet. There was an increase in his achievement of developmental milestones, but he still showed significantly delayed neuropsychiatric development (mainly in gross motor function and language) and brain myelination seven months after the start of therapy. 
Table 1 Admission and follow-up clinical and laboratory data of an infant with vitamin B12 deficiency

\begin{tabular}{|c|c|c|c|c|c|}
\hline Parameter & Admission & $\begin{array}{l}\text { Two weeks } \\
\text { after } \\
\text { admission }\end{array}$ & $\begin{array}{l}\text { Three months } \\
\text { after } \\
\text { admission }\end{array}$ & $\begin{array}{l}\text { Five months } \\
\text { after } \\
\text { admission }\end{array}$ & $\begin{array}{l}\text { Seven } \\
\text { months } \\
\text { after } \\
\text { admission }\end{array}$ \\
\hline \multicolumn{6}{|l|}{ Clinical data } \\
\hline Age, months & 5 & 6 & 8 & 10 & 12 \\
\hline Weight, g & 4,800 & 5,660 & 6,515 & 7,000 & 7,445 \\
\hline Length, cm & 60 & 61.5 & 65.5 & 67.5 & 69 \\
\hline $\begin{array}{l}\text { Head } \\
\text { circumference, } \\
\text { cm }\end{array}$ & 39 & 42 & 43.5 & 45 & 46 \\
\hline $\begin{array}{l}\text { Pathological } \\
\text { clinical findings }\end{array}$ & $\begin{array}{l}\text { Poor weight gain, feeding } \\
\text { difficulties, severe pallor, } \\
\text { muscle hypotonia, } \\
\text { somnolence, enlarged liver } \\
\text { and spleen }\end{array}$ & $\begin{array}{l}\text { Persistence of } \\
\text { hypotonia and mildly } \\
\text { enlarged liver and } \\
\text { spleen }\end{array}$ & $\begin{array}{l}\text { Persistence of mild } \\
\text { hypotonia and mildly } \\
\text { enlarged liver and } \\
\text { spleen }\end{array}$ & $\begin{array}{l}\text { Persistence of mild } \\
\text { hypotonia }\end{array}$ & Persistence of mild hypotonia \\
\hline $\begin{array}{l}\text { Pathological } \\
\text { neurological } \\
\text { findings }\end{array}$ & $\begin{array}{l}\text { Significant delay in } \\
\text { developmental milestones } \\
\text { and communicative reactions }\end{array}$ & $\begin{array}{l}\text { Significant delay in } \\
\text { developmental } \\
\text { milestones and } \\
\text { communicative } \\
\text { reactions }\end{array}$ & $\begin{array}{l}\text { Significant delay in } \\
\text { developmental } \\
\text { milestones and } \\
\text { communicative } \\
\text { reactions }\end{array}$ & $\begin{array}{l}\text { Able to remain seated } \\
\text { with } \\
\text { delay in other } \\
\text { developmental } \\
\text { milestones and } \\
\text { communicative } \\
\text { reactions }\end{array}$ & $\begin{array}{l}\text { Able to remain seated, } \\
\text { delay in gross motor function } \\
\text { and language; Griffith's scale } 86 \\
\text { (normal values, 92-100) }\end{array}$ \\
\hline
\end{tabular}

\section{Laboratory}

data

$H b, g / d L$

$\mathrm{MCV}, \mathrm{fL}$

White blood

cell count,

cells $/ \mathrm{mm}^{3}$

Platelet count cells $/ \mathrm{mm}^{3}$

Peripheral

blood

film

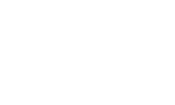

Bone marrow examination

Serum vitamin

B12, pg/mL

Serum

folic acid,

$\mathrm{ng} / \mathrm{mL}$

Serum iron,

$\mu \mathrm{g} / \mathrm{dL}$

Serum ferritin, $\mathrm{ng} / \mathrm{mL}$

Blood homocysteine, $\mu \mathrm{mol} / \mathrm{L}$

4.7
84.2
4,680
45,000
macrocytes,
poikilocytosis,
sochromia,
sochromia,
persegmented
morphonuclear
eukocytes

Reduced number of red line cells with some megaloblasts; a small number of dysplastic megakaryocytes; dysplastic granulopoiesis with asynchronous maturation processes

10
91.3
9,810
492,000

Normal

n.a.
n.a.
n.a.

n.a.

n.a.

n.a.

n.a.

n.a.

n.a.

n.a.

n.a. n.a.

n.a.

n.a.

n.a.

n.a.

n.a.

n.a.
12.2

81.2

13,410

375,000

Normal
$>2,000$

14

76

31

5.4 n.a.

n.a.

n.a.

n.a.

n.a.
1,344

17.3 
Table 1 Admission and follow-up clinical and laboratory data of an infant with vitamin B12 deficiency (Continued)

\begin{tabular}{|c|c|c|c|c|c|}
\hline $\begin{array}{l}\text { Urinary } \\
\text { methylmalonic } \\
\text { acid, } \\
\mu \text { mol/mol } \\
\text { creatinine }\end{array}$ & 281 & 6 & n.a. & n.a. & 4 \\
\hline $\begin{array}{l}\text { MMACHC gene } \\
\text { mutations }\end{array}$ & None & n.a. & n.a. & n.a. & n.a. \\
\hline \multicolumn{6}{|l|}{ Neuroimaging } \\
\hline MRI & $\begin{array}{l}\text { Mild dilatation of lateral } \\
\text { ventricles with diffuse retarded } \\
\text { myelination, most markedly in } \\
\text { the brainstem }\end{array}$ & n.a. & n.a. & n.a. & $\begin{array}{l}\text { Persistent mild dilatation of lateral } \\
\text { ventricles with diffuse retarded } \\
\text { myelination, most markedly in } \\
\text { the brainstem }\end{array}$ \\
\hline
\end{tabular}

MRI: magnetic resonance imaging; n.a.: not available.

\section{Conclusions}

This case of a 5-month-old Italian infant with severe pancytopenia and neurological impairment born to a vegan mother who had received B12 supplementation during pregnancy but not during lactation seems to be particularly interesting for various reasons.

The first is the fact that it is very important to be aware that vitamin B12 and iron deficiency can frequently occur in infants born to vegan mothers (who are increasing in number in these last years) and these deficits are a preventable cause of neurodevelopmental delay. The second is the fact that the mother was treated with a multivitamin preparation that provided $2.5 \mu \mathrm{g} /$ day of vitamin $\mathrm{B} 12$, an amount that is quite similar to the $2.6 \mu \mathrm{g} /$ day recommended for pregnant women by health authorities [5]. Despite this, the infant showed clinical signs clearly attributable to vitamin B12 deficiency (such as a failure to thrive and pallor) in the first months of life, which suggests that the recommended amount of vitamin B12 is not enough to avoid the early development of disease in the infants of strictly vegetarian women. Moreover, the concomitant presence of substantial iron deficiency modified the characteristics of the anemia and may also justify several symptoms (i.e., lethargy and irritability) and signs (i.e., demyelination and poor developmental progression). Instead of significant megaloblastosis, we found red blood cells with a normal MCV, a finding that initially made it more difficult to reach a correct diagnosis. This also underlines the need to determine vitamin B12 and iron levels in all cases of otherwise unexplained severe anemia occurring in the first months of life. Finally, the MRI data confirmed the view of Lovblad et al. [6] that the most important neurological damage due to vitamin B12 deficiency is reduced myelination, which can persist for several months even after the start of supplementation therapy.

The possible development of severe clinical signs of vitamin B12 deficiency in infants born to undernourished mothers has been repeatedly described. A recent review of 134 cases of childhood vitamin B12 deficiency published over the last 20 years found that 69 were due to maternal B12 deficiency, and that more than $50 \%$ of these were directly related to an inadequate consumption of meat and other animal products such as that usually characterising strict vegetarians [7]. The children of women with low vitamin B12 levels during pregnancy and lactation may have smaller stores of the vitamin at birth [8], and its concentration in breast milk is likely to be low [9]. Such children tend to develop signs of vitamin B12 deficiency generally not before the fourth month of life, although neonatal cases have also been reported [10].

Childhood vitamin B12 deficiency is probably significantly more frequent than usually thought. Various studies carried out in the developing world or in countries where vegetarian diets are common have shown that a large number of mothers and children have low serum vitamin B12 levels that closely correlate with albeit mild clinical problems mainly involving the central nervous system. It has been reported that approximately onethird of low-income women and children in Guatemala have deficient $(<148 \mathrm{pmol} / \mathrm{L})$ or marginal (148-220 $\mathrm{pmol} / \mathrm{L}$ ) plasma vitamin B12 concentrations, and that the lowest levels are strictly related to poor growth and development [11]. In India, where people tend to be vegetarians, vitamin B12 deficiency during pregnancy is common [12], and the infants of deficient mothers are affected by a syndrome including mild developmental regression and alterations in skin pigmentation [13].

Vitamin B12 supplementation in pregnant and lactating women, and the greater use of complementary vitamin B12-rich foods in infants aged $>6$ months are frequently suggested strategies for reducing the risk of major clinical signs of deficiency $[14,15]$. However, it is difficult to implement preventive programs in the developing world as economic problems may profoundly impact the consumption of meat and other animal products. In industrialised countries, where the problem is less frequent and only vegans are at risk, a correct evaluation of the mother's nutritional history and systematic supplementation during pregnancy and lactation can easily prevent the problem. Unfortunately, there is a 
lack of information concerning the optimal formulation of micronutrient supplements for pregnant women, and the need to continue their administration after delivery is not recognised in many situations in which maternal and infant health might benefit [16].

Despite a low vitamin B12 intake and significant deficiency, pregnant women generally show no related signs or symptoms because they usually consume large amounts of vegetables containing high folate concentrations that may mask the hematological effects of vitamin B12 deficiency. Furthermore, the neuropsychiatric symptoms of vitamin B12 deficiency are usually mild in adolescents and adults, and may therefore be overlooked.

On the contrary, young infants frequently have multiple deficiencies and so, particularly when they are exclusively breastfed, they develop hematological disease with anemia and (in the most severe cases) pancytopenia. As the developing central nervous system seems to be more sensitive to vitamin B12 deficiency than that of adults [17], breastfed infants born to vegan mothers may experience substantial neurological damage with developmental delay, irritability, tremor and convulsions. Furthermore, these may persist and lead to long-term cognitive and developmental delay despite adequate therapy and the complete disapperance of hematological problems [18].

As in our case, treated vitamin B12 and iron deficient infants tend to improve rapidly: hematological values quickly return to normal, and the neurological signs progressively decrease. However, in most of the severe cases described thus far [18], some neurological problems may be permanent.

In conclusion, this case underlines the importance of adequate maternal vitamin B12 intake during pregnancy by means of supplementation which, in the case of vegans, should be significantly greater than that usually given. Moreover, the supplementation should be continued during lactation in order to avoid the development of signs of deficiency that may be associated with persistent neurological problems in infancy. This case also highlights the need to consider vitamin B12 deficiency in infants with severe anemia even if their hematological parameters do not indicate megaloblastic anemia because the concomitant presence of substantial iron deficiency may modify the characteristics of the anemia.

\section{Consent}

The patient's parents gave their written consent to the publication of this case report.

\section{Abbreviation}

MRI: Magnetic resonance imaging

\section{Competing interests}

The authors have no competing interests.

\section{Acknowledgments}

This publication was supported by a grant from the Italian Ministry of Health (Bando Giovani Ricercatori 2007).

\section{Authors' contributions}

SG, GC and FM were responsible for making the diagnosis, treating the infant in hospital and for the follow up. SS decided the nutritional needs of the patient and his diet. NP and SE co-wrote the manuscript. All of the authors have read and approved the final manuscript.

Received: 9 April 2012 Accepted: 24 June 2012

Published: 24 June 2012

\section{References}

1. Ludwig ML, Matthews RG: Structure-based perspectives on B12dependent enzymes. Annu Rev Biochem 1997, 66:269-313.

2. Stabler SP, Allen RH, Savage DG, Lindenbaum J: Clinical spectrum and diagnosis of cobalamin deficiency. Blood 1990, 76:871-881.

3. Watkins D, Rosenblatt DS: Inborn errors of cobalamin absorption and metabolism. Am J Med Genet C Semin Med Genet 2011, 157:33-44.

4. Van Winckel M, Vande Velde S, De Bruyne R, Van Biervliet S: Clinical practice: vegetarian infant and child nutrition. Eur J Pediatr 2011, 170:1489-1494.

5. Institute of Medicine, Food and Nutrition Board: Dietary Reference Intakes: Thiamin, Riboflavin, Niacin, Vitamin B6, Folate, Vitamin B12, Pantothenic Acid, Biotin, and Choline. Washington, DC: National Academy Press; 1998.

6. Lövblad K, Ramelli G, Remonda L, Nirkko AC, Ozdoba C, Schroth G: Retardation of myelination due to dietary vitamin B12 deficiency: cranial MRI findings. Pediatr Radiol 1997, 27:155-158.

7. Quentin C, Huybrechts S, Rozen L, De Laet C, Demulder A, Ferster A: Vitamin B12 deficiency in a 9-month-old boy. Eur J Pediatr 2012, 171:193-195.

8. Baker H, Frank O, Deangelis B, Feingold S, Kaminetzky HA: Role of placenta in maternal-fetal vitamin transfer in humans. Am J Obstet Gynecol 1981, 141:792-796.

9. Specker BL, Black A, Allen L, Morrow F: Vitamin B-12: low milk concentrations are related to low serum concentrations in vegetarian women and to methylmalonic aciduria in their infants. Am J Clin Nutr 1990, 52:1073-1076

10. Erdeve O, Arsan S, Atasay B, lleri T, Uysal Z: A breast-fed newborn with megaloblastic anemia-treated with the vitamin B12 supplementation of the mother. J Pediatr Hematol Oncol 2009, 31:763-765.

11. Jones KM, Ramirez-Zea M, Zuleta C, Allen LH: Prevalent vitamin B-12 deficiency in twelve-month-old Guatemalan infants is predicted by maternal B-12 deficiency and infant diet. J Nutr 2007, 137:1307-1313.

12. Katre $P$, Bhat D, Lubree H, Otiv S, Joshi S, Joglekar C, Rush E, Yajnik C: Vitamin B12 and folic acid supplementation and plasma total homocysteine concentrations in pregnant Indian women with low B12 and high folate status. Asia Pac J Clin Nutr 2010, 19:335-343.

13. Jadhav M, Webb JK, Vaishnava S, Baker SJ: Vitamin B12 deficiency in Indian infants. A clinical syndrome. Lancet 1962, 2:903-907.

14. Thomas MR, Sneed SM, Wei C, Nail PA, Wilson M, Sprinkle EE: The effects of vitamin C, vitamin B6, vitamin B12, folic acid, riboflavin, and thiamin on the breast milk and maternal status of well-nourished women at 6 months postpartum. Am J Clin Nutr 1980, 33:2151-2156.

15. Sneed SM, Zane C, Thomas MR: The effects of ascorbic acid, vitamin B6, vitamin B12, and folic acid supplementation on the breast milk and maternal nutritional status of low socioeconomic lactating women. Am J Clin Nutr 1981, 34:1338-1346.

16. Allen LH: Multiple micronutrients in pregnancy and lactation: an overview. Am J Clin Nutr 2005, 81:1206S-1212S.

17. Dror DK, Allen LH: Effect of vitamin B12 deficiency on neurodevelopment in infants: current knowledge and possible mechanisms. Nutr Rev 2008, 66:250-255.

18. Honzik T, Adamovicova M, Smolka V, Magner M, Hruba E, Zeman J: Clinical presentation and metabolic consequences in 40 breastfed infants with nutritional vitamin B12 deficiency - what have we learned? Eur J Paediatr Neurol 2010, 14:488-495.

doi:10.1186/1471-2431-12-85

Cite this article as: Guez et al:: Severe vitamin B12 deficiency in an exclusively breastfed 5-month-old Italian infant born to a mother receiving multivitamin supplementation during pregnancy. BMC Pediatrics 2012 12:85. 